\title{
A Risk-Benefit Analysis of Antipsychotic Medication and Contingent Skin Shock for the Treatment of Destructive Behaviors
}

Nathan A. Blenkush

The Judge Rotenberg Center, 250 Turnpike Street, Canton, MA 02021, USA

\begin{abstract}
Antipsychotic medications are commonly used to address destructive behaviors in people with developmental disabilities. Contingent skin shock is less commonly employed. Here, the risks and the benefits of antipsychotic medications and contingent skin shock are enumerated and compared. First, the major untoward effects of antipsychotic medications and contingent skin shock are summarized. Second, an efficacy analysis was conducted consisting of the following components: a brief description of the conclusions of a 1991 review of antipsychotic medications; a complete analysis of the effect of first generation and second generation antipsychotics on the irritability subscale of the Aberrant Behavior Checklist; a complete analysis of first generation and second generation antipsychotics on the Clinical Global Impression - Improvement Scale; a complete analysis of the effect of first generation antipsychotics, second generation antipsychotics, and contingent skin shock on destructive behavior frequency. The results of the analysis suggest that contingent skin shock is by far the most effective procedure and has the most favorable side effect profile.
\end{abstract}

\section{Introduction}

Clinical teams comprised of psychiatrists, behavior analysts, and other professionals strive to provide the least restrictive most effective treatment to those people with developmental disabilities who exhibit destructive behaviors. Each discipline has expertise in a range of interventions. For example, the behavior analyst may be skilled at assessment of behavior function, differential reinforcement, extinction, and punishment procedures. On the other hand, the psychiatrist brings a range of pharmaceutical interventions, the ability to sign off on the use of protective equipment or mechanical restraint, and the ability to recommend electroconvulsive therapy or psychosurgery.

Destructive behaviors generally include high intensity and/or high frequency aggression, self-injury, and/or property destruction, but may include other excessive topographies or idiosyncratic responses. High intensity means the behavior(s) result in injuries to the emitter, injuries to others, or requires emergency physical interventions or protective equipment. High frequency means the behavior occurs hundreds or thousands of times per day. Generally, these behaviors force the person to live away from their family home or ideal living situation, make it difficult or impossible for them to receive an education in a typical school setting or otherwise learn new skills, and result in frequent or long-term psychiatric hospitalization.

Differing opinions exists regarding how to employ the various interventions used to treat destructive behaviors. For example, Matson and LoVullo [1] suggest using positive reinforcement methods, then adding aversives first and psychotropic medications second if necessary when treating self-injury. Wachtel and Hagopian [2] suggested a cooperative approach between psychiatry and behavior analysis in treating destructive behaviors exhibited by those with intellectual disabilities. Others have demonstrated successful treatment of destructive behaviors using differential reinforcement and punishment and, in most cases, eliminating medication [3].

There is agreement that those treating people with destructive behaviors should provide the most effective and least restrictive treatment interventions available. Within behavior analysis and psychiatry, decision making models have been proposed to aid in clinical thinking regarding aversive interventions and psychotropic medications. For example, Meinhold and Mulick [4] provided an example of a decision analysis that separated value statements from the effectiveness of treatment options, side effects, and costs associated with various interventions.

Mikkelsen [5] proposed the following equation as a guide to clinical thinking regarding psychotropic medication and people with intellectual disabilities:

$\begin{array}{lcc}\begin{array}{c}\text { Probability of } \\ \text { Success }\end{array} & \begin{array}{c}\text { Symptom } \\ \text { Severity }\end{array}\end{array}$

\section{Side Effect Profile}

Mikklesen classified psychotropic medication side effect profiles into categories of severity based on extant literature, encouraged neutral data collection methods, and suggested examination of the literature and/or analysis of one's clinical experience to identify the probability of success of a particular drug intervention.

The models proposed by Meinhold and Mulick [4] and Mikklesen [5] have in common the need to identify the risks and benefits of treatment options. Treatment interventions that most would considerto possess minimal risk include pharmacological interventions with extremely mild side-effect profiles and functionbased behavioral interventions such as functional communication training [6], differential reinforcement of alternative and differential reinforcement of incompatible behaviors [7], non-contingent reinforcement [8], antecedent manipulations [9], and extinction [10].

"Corresponding Author: Dr. Nathan Blenkush, The Judge Rotenberg Center 250 Turnpike Street, Canton, MA 02021, USA; E-mail: n.blenkush@judgerc.org

Citation: Blenkush N (2017) A Risk-Benefit Analysis of Antipsychotic Medication and Contingent Skin Shock for the Treatment of Destructive Behaviors. Int J Psychol Behav Anal 3: 121. doi: http://dx.doi.org/10.15344/2455-3867/2017/121

Copyright: @ 2017 Blenkush. This is an open-access article distributed under the terms of the Creative Commons Attribution License, which permits unrestricted use, distribution, and reproduction in any medium, provided the original author and source are credited. 
Function-based behavioral treatments continue to be refined. However, the derived procedures are not universally effective. First, in a certain percentage of the published literature, assessment results show that some problem behaviors are maintained by multiple factors or by automatic or unknown reinforcers [11]. Second, even if the behavior function is identified, the prescribed function based intervention, even with the addition of punishment components, is not always effective [12]. If such procedures are ineffective, the next set of treatment/management options include the following: frequent physical restraint; continuous mechanical restraint/ protective equipment; antipsychotic medication and polypharmacy; and contingent skin shock. In addition, psychosurgery [13] and electroconvulsive therapy [14] have been described.

In 1989, the National Institute of Health held a consensus development conference to examine destructive behaviors and associated treatments in people with developmental disabilities. The final report was controversial [15] and called for more research. Since 1989, new treatments and new information regarding existing treatments has been published. New atypical antipsychotic drugs including clozapine, risperidone, olanzapine, quetiapine, ziprasidone, aripiprazole, and paliperidone were introduced in the United States in 1989, 1994, 1996, 1997, 2001, 2002, and 2006 respectively. Increasingly, these medications have been prescribed to address destructive behaviors exhibited by people with developmental disabilities. New information about contingent skin shock is also available.

In this paper, the efficacy and side effect profiles of first generation antipsychotic medications (FGAs), second generation antipsychotic medications (SGAs), and contingent skin shock (CSS) are summarized and compared.

\section{Side Effect Profiles}

\section{Side Effect Profile of First Generation Antipsychotic Medications}

The side effects of FGAs include acute extrapyramidal syndromes, chronic extrapyramidal syndromes, neuroleptic malignant syndrome, weight gain, sexual dysfunction, seizure, prolactin level elevation, and sudden cardiac death, among other side effects.

Marder and van Kammen [16] describe acute extrapyramidal syndromes including akathisia, dystonia, and drug induced parkinsonism. Akathisia may be characterized by a feeling of inner restlessness, an inability to sit still, or an urge to walk or initiate movement. Akathisia has been reported to occur in $62 \%(41 \%$ - mild; $21 \%$ - moderate to severe) of those taking FGAs. Acute dystonias consists of muscle spasms of the head and neck and involuntary movements. These reactions occur in $40 \%$ of those treated with high potency FGAs (e.g. pimozide, fluphenazine, haloperidol) who do not also receive antiparkinsonian medications. Finally, drug induced parkinsonism, comprised of rigidity, bradykinesia, shuffling gait, and tremor, occur in approximately $30 \%$ of those chronically treated with FGAs. Anticholinergic medications are often effective in treating extrapyramidal side effects but are associated with an additional set of side effects. Extrapyramidal signs have been reported to occur in children treated with FGAs at percentages ranging from $25-73 \%$ [17]. Casey [186] summarized the clinical presentation of tardive dyskinesia (TD) in the following way:

Tardive dyskinesia is characterized by repetitive, involuntary, purposeless movements. The typical signs include chewing; tongue protrusion; vermicular tongue activity; lip smacking, puckering, and pursing; or paroxysms of rapid eye blinking. Choreoathetoid movements in the limbs and trunk can also occur. Dyskinesias in the fingers may look as if the patient is playing an invisible guitar or piano. Very rarely TD produces aerophagia, irregular respiratory rates, and grunting noises.

Generally, approximately $3 \%$ of those receiving typical antipsychotic drugs will develop persistent (lasting more than 3 months) cases of TD each year; approximately $2 \%$ per year will develop transient TD (lasting less than 3 months) [19]. Further, the cumulative incidence of TD has been reported at $5 \%, 27 \%, 43 \%, 52 \%, 56 \%$ at $1,5,10,15$, 20 years respectively [20]. If one does develop TD, recovery rates at 3 month have been reported at $24 \%, 40 \%$, and $81 \%$ [21]. Generally, the probability of developing TD is related to age; with TD less common in children and adolescents and most common in the elderly.

Levenson [22] described major and minor features of neuroleptic malignant syndrome (NMS). Major features include fever, rigidity, and elevated creatine phosphokinase concentration (suggesting injury or stress to the heart, brain, or muscle tissue). Minor features include tachycardia, abnormal arterial pressure, tachypnoea, altered consciousness, diaphoresis, and leukocytosis. The probability of developing NMS is estimated to range from $.07 \%{ }^{1}$ to $2.2 \%$ per year [23]. Marder and van Kammen [16] suggest that 20 to $30 \%$ (or more) of well-developed cases of NMS are fatal.

Allison et al. [24] estimated the effects of FGAs on weight gain in adults at 10 weeks of treatment. For the FGAs molindone, fluphenazine, haloperidol, chlorpromazine, and thioridazine, they found estimated mean weight changes of $-.81, .43, .48,2.10$, and 3.49 $\mathrm{kg}$ respectively. Allison et al. noted that weight gain clearly increased with time and that patients taking the drugs for long periods of time would be expected to gain more weight. Aronson [17] noted significant weight gain in nearly $100 \%$ of children treated with FGAs. Obesity, of course, is associated cardiovascular diseases, diabetes, cancer, and other maladies [25].

FGAs affect sexual functioning. Erectile dysfunction has been reported in 23 to 54 percent of men receiving FGA treatment [16]. Sexual dysfunction varies among FGAs. For example, Serretti and Chiesa [26] found that perphenazine, haloperidol, and thioridazine were associated with sexual dysfunction in 25,46 , and 60 percent of patients respectively. They suggest that FGAs may affect sexual function by inhibiting motivation and reward, increasing sedation, and reducing peripheral vasodilation.

Seizures have been reported to be associated with FGAs. When examining incidence of seizures, Allredge [27] pointed out that seizures have been reported to occur in the general population at an annual incidence of .073 to $.086 \%$. Aronson [17] (2 reports seizures to occur in probably less than $1 \%$ of those prescribed these drugs (p. 203). Logothetis [28] compared seizure incidence in 859 patients treated with phenothiazines and 669 patients not so treated. Seizure incidence was equal to $1.2 \%$ for those treated with phenothiazines and $0.0 \%$ for those not treated with a phenothiazine. Seizures occurred in $9 \%$ of those prescribed a high dose $(1000 \mathrm{mg} /$ day or more of chlorpromazine or equivalent) compared to $.3 \%$ prescribed a low dose (200 mg/day or less). On the other hand, Pauig, Deluca, and Osterheld [29] found that seizures rates improved or remained unchanged in 64 of 100 patients with epilepsy receiving thioridazine.

Prolactin levels can be affected by FGAs. Rosenbloom [30] summarized studies describing the effect of antipsychotic medication 
on prolactin levels. A combination of 4 studies showed that of 56 children receiving a mean does of $14.2 \mathrm{mg} /$ day of haloperidol, $90 \%$ had prolactin levels greater than the upper limit of what is consider to be normal. As a result $6.7 \%$ had gynecomastia and 15.4 had irregular menstrual cycles. A combination of 3 studies showed that of 46 children receiving $3.7 \mathrm{mg} /$ day of pimozide, $80 \%$ had prolactin levels great than the upper limit of what is considered normal (reports regarding gynecomastia and menstrual cycles were absent). Madhusoodanan, Parida, and Jimenez [31] summarized two studies showing a dose dependent increase in prolactin in $40-90 \%$ of those treated with phenothiazines. Crawford, Beasley, and Tollefson [32] summarized the effect of haloperidol on prolactin levels of 69 adults and found $72 \%$ had elevated prolactin levels. In addition to contributing to galactorrhea, amenorrhea, gynecomastia, and sexual dysfunction, hyperprolactinemia may impact peak bone mass attainment and bone mineral density [30].

FGAs have been associated with sudden cardiac death. Recently, Ray, Chung, Murray, Hall, and Stein [33] summarized data associated with 90,307 (44,218 typical; 46,089 atypical) antipsychotic drug users and 186,600 matched nonusers of antipsychotic drugs between the ages of 30 and 74 . They found higher rates of sudden cardiac death in users of FGAs when compared to nonusers and reported incident rate ratios of 1.99 (95\% confidence interval [CI], 1.68 to 2.34). Put another way, over the course of 1 year approximately 1 in 700 nonusers died of sudden cardiac death. For those prescribed FGAs, over the course of 1 year, approximately 2 in 700 died of sudden cardiac death. In addition, the risks varied with respect to drug and dose. For example, those prescribed high doses of thioridazine over the course of 1 person year, approximately 5 in 700 died of sudden cardiac death. The risk of sudden cardiac death was dose dependent as those receiving higher doses died more frequently than those who received lower doses. In addition, sudden cardiac death was 10 times more likely in the 70-74 age group than the 30-34 age group.

Sedation is a common side effect of FGAs. Lehman et al. [34], in the American Psychiatric Association Practice Guidelines for the Treatment of Patients with Schizophrenia, suggest the following: "Most patients experience some sedation, particularly with the lowpotency first-generation agents such as chlorpromazine, but it occurs to some extent with virtually all antipsychotic medications."

Finally, typical antipsychotic medications have been associated with venous thromboemolism [35], hypotension, and QT prolongation (especially thioridazine) which potentially could contribute to sudden death [17].

\section{Side Effect Profile of Second Generation Antipsychotic Medications}

The side effects of SGAs include acute extrapyramidal syndromes, chronic extrapyramidal syndromes, neuroleptic malignant syndrome, weight gain, sexual dysfunction, seizure, prolactin-level elevation, among other side effects. Generally, SGAs cause acute extrapyramidal side effects at similar rates when compared to low potency FGAs (e.g. chlorpromazine, thioridazine) [36]. Only case reports of acute dystonic reactions have been reported with SGAs [36]. Miller et al. [37] reported that $37-44 \%$ of people taking olanzapine, quetiapine, risperidone, or ziprasidone met at least one of three criteria for parkinsonism for 1 year or less. They also described akathisia occurring in $26-35 \%$ of those treated with SGAs.
In the past, SGAs, in relation to FGAs, were thought to be much less likely to cause TD. However, recent studies and reviews have not confirmed this assertion. In a recent review, Tarsy, Lungu, and Baldessarini [19] concluded the following:

The sparring of risk of TD with modern APDs [antipsychotic drugs] is surprisingly modest and less than is generally assumed. In fact, as reviewed above, TD risk may not be substantially lower than with some older APDs, especially those of low or moderate potency, including perphenazine, mesoridazine, molindone, and thioridazine. (pp 611-612; bracketed material supplied).

Correll and Shenk [38] found annual TD rates of 5.5 and 3.9\% respectively for FGAs and SGAs respectively. Woods et al. [39] compared prevalence, incidence, and severity of TD in a 352 patient cohort who received treatment with antipsychotic medication between 2000 and 2005 with a 362 patient cohort who received treatment at the same mental health center in the 1980's (prior to the introduction of SGAs). Despite the fact that only $36 \%$ received FGAs in the 2000-2005 cohort, the prevalence, incidence, and incident case of severity of TD were equivalent.

Troller, Chen, and Sachdev [40] reviewed the literature related to SGAs and NMS. They described NMS associated with all SGAs and concluded that, with the exception of clozapine (which was less associated with rigidity), NMS induced by SGAs looked the same as NMS induced by FGAs. Finally, they noted that it was not clear whether any SGAs was more or less likely to cause NMS when compared to FGAs.

SGAs have been associated with significant weight gain. For example, Allison et al. [24] estimated that clozapine, olanzapine, risperidone, and ziprasidone were associated with weight increases of $3.99,3.51,2.00$, and $0.04 \mathrm{~kg}$ respectively after 10 weeks of treatment. Correll et al. [41] evaluated the effects of first time SGAs treatment on weight gain in 272 children aged 4-19 years. After a median of 10.8 weeks of treatment, aripiprazole, risperidone, quetiapine, and olanzapine were associated with mean weight increases of 4.44, 5.34, 6.06 , and $8.54 \mathrm{~kg}$ respectively. Those untreated gained a mean of 0.19 $\mathrm{kg}$. Many of the drugs had a negative effect on metabolic parameters such as insulin, cholesterol, and triglycerides.

SGAs have been associated with sexual dysfunction. Serretti and Chiesa [26] summarized total sexual dysfunction reported in the literature regarding SGAs. They reported clozapine, risperidone, olanzapine, aripiprazole, ziprasidone, and quetiapine to be associated with sexual dysfunction in $52,43,40,27,19$, and $16 \%$ of patients respectively. However, they pointed out that, with the exception of risperidone and clozapine, rates of sexual dysfunction were lower in studies where concomitant use of other drugs was prohibited.

This risk of seizure associated with SGAs is variable. Devinsky, Honigfeld, and Patin [42] reviewed 1418 people treated with clozapine and found that $2.8 \%$ experience seizures ( $4.4 \%$ of those prescribed 600 mg per day or more; $1 \%$ of those prescribed $300 \mathrm{mg}$ per day or less). Alper, Schwartz, Kots, and Kahn [43] found clozapine and olanzapine to be associated with more frequent seizures upon examination of Phase II and III clinical trials.

Among SGAs, risperidone is most likely to cause increases in prolactin. Upon review of the literature, Roke, van Harten, Boot, and Buitelaar [44] found that risperidone, olanzapine, and quetiapine were 
associated with hyperprolactinaemia in 62,31 , and $12 \%$ of children respectively. On the other hand, clozapine and ziprasidone did not increase prolactin levels.

Ray et al. [33] examined sudden cardiac death associated with clozapine, olanzapine, quetiapine, and risperidone. They found that these second generation drugs were associated with same degree of risk as first generation drugs and that risk was dose dependent. That is, within the sample of people aged 30-74, approximately 2 in every 700 people per year taking an SGA died of sudden cardiac death compared to 1 in 700 not taking an SGA or FGA.

Clozapine can cause agranulocytosis which is the suppression of bone marrow's production of infection fighting white blood cells (leaving the person vulnerable to infection) [45]. In Finland, clozapine was originally introduced in 1975 to 2260 people. During that year, 16 (.70\%) experience agranulocytosis and $8(.35 \%)$ died as a result. de la Chapelle, Kari, Numinen, and Hernberg [46] estimated the incidence rate at 2.1/1000 patient-months. Using their analysis, for every 80 people given clozapine for one year, 2 developed agranulocytosis and 1 in 80 died as a result. The introduction of regular blood tests and national patient registries significantly reduced the risk of agranulocytosis. Specifically, Honigfeld [47] found that of 99,502 people receiving clozapine in the US between 1990 and 1994, .38\% (378 people) experienced agranulocytosis and $.01 \%$ (12 people) died as a result.

SGAs have been associated with nocturnal enuresis. HarrisonWoolrych, Skegg, Ashton, Herbison, and Skegg [48] evaluated the associated between nocturnal enuresis and clozapine, olanzapine, quetiapine, and risperidone in people between the ages of 15 and 64 Enuresis occurred in 20.7 (17 of 82), 9.6 (11 of 115), 6.7 (7 of 105), and 6.2 (12 of 195) percent of those taking clozapine, olanzapine, quetiapine, and risperidone respectively. For $65 \%$ of the participants, nocturnal enuresis occurred on multiple occasions.

Additional side effects, save weight gain, associated with SGAs are presented in Tables 1-4 (Supplementary File). For all tables, only the name of the first author is listed for the sake of brevity. In Tables 1-4, the side effects reported in the studies examined for efficacy (described later in this paper) are summarized. In Table 1, the side effects, in the placebo controlled studies are presented. Every side effect, the number of times it was reported, the number of people in the group the side effect was reported in, and associated percentage are reported for drug and placebo groups. In Table 2 [49-57] side effects such as sedation, somnolence, fatigue, etc. are grouped together and presented adjacent to placebo groups. Table 2 shows that $52 \%$ of those who received an SGA experienced some sedation/somnolence/fatigue type effect compared to $13 \%$ who were given placebo. Table 3 summarizes the side effects reported in studies without a placebo control. Table 4 [53, 58-85], shows side effects such as sedation, fatigue, somnolence, etc. from studies without a control group grouped together. Table 4 shows that 40 percent of those given SGAs experienced some sedation/ somnolence/fatigue type effect.

\section{Side Effect Profile of Contingent Skin Shock}

In order to properly compare the side effects of contingent skin shock with the side effects associated with antipsychotic medications, it is important to classify side effects. There seems to be two kinds of side effects. First, there are specific side effects to the body. Second, there are side effects associated with behavior that were unintentional but beneficial or unintentional and disruptive or harmful. Here, all of these effects are reviewed with respect to CSS. However, it is important to point out that problem behaviors such as crying, escape behaviors, and noncompliance surrounding the administration of oral and/or intramuscular antipsychotic medication are not described in the typical drug study. Nor is the pain one experiences when medication is injected or venipuncture is required to monitor drug levels or side effects. Indeed, some children consider needles to be extremely painful and fear inducing [86]. In addition, examination of positive/negative changes in mood, learning, affection, appropriate behavior, inappropriate behavior are not necessarily part of typical side effect detection net for medications. This is not to say that such effects do not occur. Indeed, some researchers have noted improved response to behavior intervention plans $[87,88]$ with the addition of antipsychotic medications.

Lichstein and Schreibman [89] reviewed the side effects described in studies employing CSS and noted that the majority of the reported effects were positive in nature. Matson and Taras [90] reviewed 382 applied studies related to punishment (including studies with CSS as an independent variable) between 1967 and 1989. They found positive side effects were reported 212 times while negative side effects were reported 16 times. In this paper the side effects found in CSS studies since 1989 are summarized.

The obvious effect of CSS is pain caused when the electrical current stimulates nociceptors and sensory receptors. The pain only lasts as long as the current is passing through the skin. Mudford, Boundy, and Murray [91] reported superficial pin-point burn marks from sparks arcing from a Hot Shot Sabre Six Device to the skin. This is the only device that is described to cause these tiny pinpoint burns. Mudford [91] also reported a slight local tremor in the thigh during activation of a CSS device (Therapuetic Shock Device). Israel et al. [3] reported the occasional discoloration of the skin remaining for a few minutes or days. Otherwise, no physical side effects have been reported. None of these side effects resulted in termination of treatment with CSS. However, Mudford [91] replaced the device that caused superficial pin-point burns with a device that did not cause such superficial pinpoint burns.

Negative behavioral effects have been reported. Duker and Seys [92] described extreme anxiety (screaming, crying, attack, and escape) during the initial CSS treatment sessions in 5 of 12 participants. However, these responses subsided and only returned when the CSS device was removed from their body. They also described one participant who froze (made no responses) during the initial CSS treatment session. Duker and Seys [93] describe providing relaxation training in the presence of panic or anxiety during the initial CSS presentation. Israel, Blenkush, von Heyn, and Rivera [3] indicated some individuals emitted avoidance responses (such as removing the device or grabbing the transmitter). Other negative behaviors mentioned included temporary emotional behavior and tensing of the body. None of the negative behavioral side effects resulted in discontinuation of treatment with CSS.

The majority of the side effects reported in the literature associated with CSS are positive in nature. For example, Duker and Van den Munckhof [94] found those treated with CSS experienced increased stress when the CSS device was removed. Table 5 (Supplementary File) [91, 95-102] presents the positive behavioral effects derived from studies regarding CSS since 1989. Generally, decreases in problem 
behaviors not treated with CSS, improvements in appropriate behaviors, overt happiness, and improvement in skill acquisition are commonly described.

\section{Efficacy}

\section{Overview of dependent variables}

A number of different dependent variables have been used to measure the effect of FGAs and SGAs on destructive behaviors exhibited by people with developmental disabilities. The most common dependent variables are subjective ratings scales. Among the rating scales, the Clinical Global Impression - Improvement (CGI-I) scale [103] and the irritability subscale of the Aberrant Behavior Checklist (ABC-I) [104] are often used to describe the effect of a drug on destructive behaviors of the developmentally disabled.

The CGI-I scale instructions ask the rater (the attending clinician) to "rate total improvement whether or not, in your judgment, it is due entirely to drug treatment. Compared to his condition at admission to the project, how much has he changed?" [103]. The rater selects from the following numbered options: (0) not assessed, (1) very much improved, (2) much improved, (3) minimally improved, (4) no change, (5) minimally worse, (6) much worse, (7) very much worse. Generally, those classified as very much improved or much improved are considered responders.

The ABC-I [104] is comprised of the following 15 items: injures self, aggressive to other patients and staff, screams inappropriately, temper tantrums, irritable, yells at inappropriate times, depressed mood, demands must be met immediately, cries over minor annoyances and hurts, mood changes quickly, cries and screams inappropriately, stamps feet while banging objects or slamming doors, deliberately hurts self, does physical violence to self, and throws temper tantrums when he/she does not get own way. The rater indicates whether a particular item is not a problem at all (0), a slight problem (1), a moderate problem (2), or a severe problem (3). Thus, the maximum score is 45 and the minimum score is 0 . The rater is asked to consider the experiences of others caring for the person and whether the behavior interferes with development, functioning, or relationships. The rater is also asked to consider relative frequency. Specifically, the instructions state the following:

Take relative frequency into account for each behavior specified. For example if the client averages more temper outbursts than most other clients you know or most others in his/her class, it is probably moderately serious (2) or severe (3) even if these occur only once or twice a week. Other behaviors, such as noncompliance, would probably have to occur more frequently to merit an extreme rating. [105].

The reliability and validity of the complete Aberrant Behavior Checklist (ABC) (comprised of 58 total items, 15 of which make up the irritability subscale) are summarized in the ABC manual [104]. With respect to reliability, the scale has high internal consistency and test-retest reliability. The authors report mean Spearman correlations to be equal to .63 (.55 for the irritability subscale). Criterion group validity was demonstrated by showing that those with higher scores (indicating more problematic behaviors) were less likely to attend training facilities (because of the difficulty of their behavior). In addition, the authors showed that those people with down syndrome scored lower on the subscales of irritability, stereotypic behaviors, and hyperactivity than those without down syndrome confirming similar findings of past researchers. Convergent and discriminant validity were demonstrated by comparing $\mathrm{ABC}$ scores with scores on several other scales. Finally, the scale was found to correlate with behavioral observations on all scales save the irritability scale. Low rates of behavior and large amounts of variability in the behaviors associated with the irritability subscale did not produce a statistically significant difference.

The aforementioned scales are most often used to evaluate the effect of a drug on problem behaviors. However, there are a number studies where the frequency of a problem behavior is described during a control and drug condition. In the case of contingent skin shock, behavior problem frequency is, almost exclusively, used to evaluate efficacy. Frequency data, of course, is a superior dependent variable because it is a direct measurement thereby eliminating observer bias and test validity [106]. Johnston and Pennypacker [107] provide a complete description of the advantages of frequency as a dependent variable.

Studies were included for analysis if ABC-I, CGI-I, or frequency data were reported. If multiple doses of a drug were used or several baseline or placebo conditions were present, the placebo condition with the highest $\mathrm{ABC}-\mathrm{I}$ score and the drug condition with the lowest ABC-I score or was utilized for the comparison. In most cases, CGI-I and frequency data was readily accessible. However, in a few cases, CGI-I and frequency data were estimated from a graphic because raw data were not reported. Those studies that utilized time sampling were also included. However, partial interval time samples were converted to frequency by assuming that only one behavior occurred within each interval. For example, if 10 -second samples were taken for 60 minutes and the behavior occurred in $50 \%$ of the intervals, the response was described as occurring 180 times per hour. To allow for comparisons, all frequency data was converted to frequency per day. A day was considered to be composed of 16 waking hours. Therefore, responses per minute, hour, day, week, month, and year were converted to responses per day by respectively multiplying each by $960,16,1,1 / 7$, $1 / 30,1 / 365$. For CSS data, the mean baseline frequency was the mean of all baseline data points. Generally, the last three reported data points or data describing the end result of the treatment were used to calculate the mean treatment frequency.

\section{Efficacy of First Generation Drugs}

First generation antipsychotic study selection: Studies describing the efficacy of FGAs were obtained in two ways. First, all of the studies listed by Thompson, Hackenberg, and Schaal [108] in Table D-1 (p.374-375) were obtained. In addition, all single subject design studies they cited within the section on neuroleptics were obtained. Second, PubMed and PsychINFO searches (limited to the period between 1990 and 2011) were performed with search terms such as "neuroleptic", "antipsychotic", "developmental disability", "autism", "intellectual disability", as well as the brand and generic names of FGA. Finally, the reference sections of obtained articles were examined.

Review methodology: First, to describe the efficacy of FGAs in treating destructive behaviors the conclusions of a previous review are summarized. Second, because only six relevant studies since 1990 were found, each is briefly reviewed. Finally, ABC-I, CGI-I, and frequency data derived from the previous review and six studies since 1990 are described.

1991 Conclusions: Thompson, Hackenberg, and Schaal [108] summarized studies between 1971 and 1989 where FGAs were used to treat destructive behaviors in people with developmental disabilities. 
After reviewing a series of studies related to chlorpromazine, they stated the following:

In summary, the literature concerning the therapeutic effects of chlorpromazine on the problem behaviors of people with mental retardation suggests that, although in some cases some therapeutic benefit has been observed, in most cases it was either (1) not observed, (2) observed, but at the expense of adverse side effects, (3) observed, but perhaps not to a clinically-relevant degree, (4) observed, but inferior to behavioral treatments, or (5) observed, but inferior to other drug treatments.

Regarding thioridazine, the authors again noted the variability in efficacy and concluded the drug was likely more effective than chlorpromazine, especially in reducing stereotypical behavior Regarding haloperidol, the authors concluded the findings from the literature suggested a range of efficacy from ineffective to highly effective. The authors concluded these drugs can result in beneficial effects in addressing certain behavior disorders. However, because of issues associated with measurement, heterogeneity of participant samples, and absence of functional diagnosis of behavior problems, they noted it was difficult to state which individuals with which behavior disorders were likely to benefit.

1990-2011 review: Since 1990, it appears that no further research has been conducted specifically on the efficacy of chlorpromazine as a treatment for destructive behaviors. However, there have been a few new research studies addressing the efficacy of other FGAs.

Singh, Landrum, Ellis, and Donatelli [109] found that thioridizine at $1.25 \mathrm{mg} / \mathrm{kg}$ was effective in reducing stereotypy (measured by percentage of 10 second intervals of occurrence) in three participants with mental retardation. Specifically, during baseline, the participants engaged in stereotypy in $84.3,87.4$, and $63.3 \%$ of intervals respectively. During the last 5 days of treatment with thioridazine, the percent of intervals with stereotypy decreased to 51.4, 61.6, and $32.4 \%$ respectively. Treatment with thioridazine was also associated with increases in social behavior. However, a response contingent 10 second visual screening was more effective than thioridazine in reducing stereotypy and resulted in higher percentages of intervals with appropriate social behavior.

May et al. [110] described the effect of the gradual removal of thioridazine from 23 adults with developmental disabilities between 1989 and 1993. They found the participant could be classified into one of three groups. For 9 participants, problem behavior frequency increased and subsequently decreased. For 5 participants, problem behavior frequency progressively decreased. For the remaining 9 participants, problem behavior frequency steadily increased. Seven of 9 who experienced regression continued to require psychotropic medication.

Mace, Blum, Sierp, Delaney, and Mauk [111] contrasted the efficacy of haloperidol or placebo and behavior treatments based on function (e.g. extinction, differential reinforcement of alternative behavior, scheduled breaks) in treating self-injurious behaviors in 15 people with developmental disabilities. The functional analysis condition associated with the highest rate of self-injury served as the study baseline. Participants were randomly assigned to receive one of two treatments; haloperidol only or placebo plus behavioral treatment. If either treatment was unsuccessful in reducing self-injury by $75 \%$ or more, the other treatment was substituted. Two participants received haloperidol continuously (because of concerns about withdrawing the drug), 8 were assigned to haloperidol only, and 5 were assigned to placebo and behavior treatment. The haloperidol only intervention was successful in reducing self-injury in 2 of 8 participants by 98.9 and $100 \%$. When behavioral procedures and placebo were substituted for haloperidol, the following percent reductions were observed: 100; $72.8 ; 11.4 ; 80.8 ; 90.3$ (one participant dropped out before exposure to the behavioral procedure and placebo). All five participants assigned to receive behavioral treatment plus placebo achieved the following percent reductions in self-injury: $92.3 ; 98.7 ; 100 ; 100 ; 96.1$. The two participants who received haloperidol continuously plus behavioral intervention experienced a $100 \%$ reduction. The researchers also contrasted scores on $\mathrm{ABC}$ at baseline and after haloperidol treatment. No significant differences were noted between any subscales.

Janowsky, Barnhill, Shetty, and Davis [112], in a retrospective chart review spanning 1990 - 1997, described the experience of FGA dose reduction or discontinuation in 136 adults with disabilities. Of the 136, 53 were withdrawn successfully; 18 were withdrawn but continued some non-antipsychotic medication; 31 continued on FGA or were switched to SGA; 34 people failed during a FGA reduction or discontinuation and required a resumption or increase of the reduced or discontinued drug.

Miral et al. [113] found that haloperidol reduced scores on the ABC from 67.1 to a statistically significant 45.8 after 12 weeks of treatment. In addition, those exposed to haloperidol showed statistically significant improvement in 4 of 5 subscales of the Ritvo-Freeman Real Life Rating Scale (RF-RLRS), Clinical Global Impression Scales, and Turgay DSM-IV PDD Rating Scale (TDPDD). In a related study, Gencer et al. [114] continued to follow the same participants for an additional 12 weeks, thus creating a 24 week evaluation period. All of the improvement in RF-RLRS and ABC scores reported by Miral et al. [113] were absent after 16 weeks in those treated with haloperidol. At 24 weeks, haloperidol reduced scores on the ABC from a mean of 67.1 to a mean of 58.1 and reduced scores on the TDPDD from 77.6 to 66.2. Only the change in TDPDD scores were statistically significant.

Tyrer et al. [115] randomly assigned 86 adults with developmental disabilities who exhibited aggressive behaviors to receive risperidone, haloperidol, or placebo. The bottom line finding was that there was no difference between the groups as measured by several rating scales (MOAS, ABC, CGI).

ABC-I: Three studies employing FGA as an independent variable and the $\mathrm{ABC}-\mathrm{I}$ as a dependent variable have been conducted. White and Aman [116] used a double blind, placebo controlled, crossover design to examine the effect of pimozide on several dependent variables used to measure the behavior of 8 people with moderate to profound mental retardation. ABC-I scores during placebo and pimozide treatment were 24.2 and 18.93 .

Aman and White [117] compared low, high, and individualized doses of thioridazine with placebo in 10 people with mental retardation. ABC-I scores associated with low, high, individualized, and placebo were $4.15,5.18,4.51$, and 4.85 respectively.

Aman, Teehan, White, Turbott, and Vaithianathan [117] compared ABC-I scores of 20 mentally retarded people aged 12-35 years while receiving placebo, a low dose of haloperidol, or a high dose of haloperidol.ABC-Iscoresassociated with placebo,lowdosehaloperidol, and high dose haloperidol were $7.02,5.68$, and 7.00 respectively. 
However, when the participants were divided according to degree of stereotypy, ABC-I scores for those with low stereotypy classifications were $3.17,3.71$, and 5.42 for the placebo, low and high dose conditions. The ABC-I scores of those with high stereotypy classifications were $12.81,8.62$, and 9.38 for the placebo, low, and high dose conditions.

In summary, three studies show the mean ABC-I change from baseline/placebo to the FGA drug condition was 3.39 (range .7-5.27). This information was derived by comparing the highest baseline/ placebo ABC-I score with the lowest ABC-I score in any drug condition.

CGI-I: Perry et al. [119] found that 33 of 59 participants with autism treated with haloperidol for 6 months were rated as much or very much improved on the CGI-I. However, participants were selected for the study because of previous positive responses to haloperidol.

Frequency Data. Four studies, describing the individual effect of FGAs on destructive behaviors of 13 individuals are summarized in Table 6 (Supplementary File) [109, 120-122]. In total, the effect of FGAs on 55 individual behaviors are summarized. Table 6 shows the converted frequency per day with placebo or the absence of a FGAs, the converted frequency per day with the FGAs, the percentage increase or decrease, as well as the multiply or divide by factor.

In the left hand third of Table 7 (Supplementary File) under FGAs, the number of behaviors reduced by various percentages is presented. Table 7 shows that 6 of 55 behaviors were reduced by $90 \%$ or more; 11 of 55 by $50 \%$ or more; and that 22 of 55 behaviors continued to occur at the same rate or increased in frequency. Of the 6 behaviors reduced by $90 \%, 4$ were reduced by $100 \%$.

Table 8 (Supplementary File) $[110-111,117-118,123]$ shows the effect of FGAs on the destructive behaviors of 161 people across 5 studies. Only one of nine behaviors showed a $>25 \%$ reduction in destructive behaviors

\section{Efficacy of Second Generation Drugs}

Second generation antipsychotic study selection: PubMed and PsychINFO searches were performed with search terms such as "neuroleptic", "antipsychotic", "developmental disability", "autism", "intellectual disability", as well as the brand and generic names of each second generation antipsychotic medication. Finally, the reference sections of obtained articles were examined. Studies were included for analysis if any of the following dependent variables were used: ABC-I; CGI-I; or problem behavior frequency.

Review methodology: ABC-I, CGI-I, and frequency data were extracted and tabulated. The effect of SGA on each dependent variable is summarized below.

ABC-I: The ABC-I scores are summarized in Table 9 (Supplementary File) [49-81, 115, 124-127]. ABC-I scores taken before the administration of drug or placebo are listed in the baseline column. The last ABC-I score obtained in each study is listed in the endpoint column. For those studies with a placebo control, the mean baseline score in the drug groups was 23.69 while the mean score at endpoint was 11.39. For the placebo group, the mean score at baseline was 24.09 and the mean score at endpoint was 18.64. Thus, in the drug groups, the mean change from baseline to endpoint was 12.3 points on the ABC-I. In the placebo groups, the mean change from baseline to endpoint was 5.75. If the placebo effect is subtracted from the drug effect, 6.55 ABC-I points separated the drug and placebo groups.
For those studies without a placebo, the mean baseline ABC-I scores was 20.93 and the mean score at endpoint was 12.15 , a difference of 8.78 points.

CGI-I: For those studies with a control group, of a possible 427 people, 230 were rated as much or very much improved $(53.9 \%)$ on the CGI-I. For placebo, 54 or 329 (16.4\%) were rated as much or very much improved.

For those studies without a control group, 246 of 429 (57.3\%) were rated as much or very much improved.

Frequency Data: Eight studies, describing the individual effect of SGAs on destructive behaviors of 88 individuals are summarized in Table 10 [82-85, 128-130]. In total, the effect of SGAs on 136 individual behaviors is summarized. Table 10 (Supplementary File) shows the converted frequency per day with placebo or the absence of a SGAs, the converted frequency per day with the SGAs, the percent increase or decrease, as well as the multiply or divide by factor.

In the center third of Table 7 under SGAs, the number of behaviors reduced by various percentages is presented. Table 7 shows that 34 of 136 behaviors were reduced by $90 \%$ or more; 90 of 136 by $50 \%$ or more; and 20 of 136 behaviors continued to occur at the same rate or increased in frequency. Of the 34 behaviors reduced by $90 \%$ or more, 23 were reduced by $100 \%$.

Table $11[77,131]$ summarizes group designs describing behavior frequency. Two studies, describing the effect of SGAs on 93 people across 11 behaviors are described. Table 11 (Supplementary File) shows that 8 of 11 behaviors were reduced by $59 \%$ or more.

\section{Efficacy of Contingent Skin Shock}

Contingent skin shock study selection: Peer reviewed studies were drawn from a list maintained at the follow web address: http://www. effectivetreatment.org/bibliography.html. Reference sections of obtained articles were also examined.

Review methodology: Frequency data were extracted and tabulated. The effect of CSS on problem behavior frequency is summarized below.

Frequency Data: Thirty-two studies, describing the individual effect of CSS on destructive behaviors of 114 individuals are summarized in Table 12 (Supplementary File) [3, 95, 97-100, 102, 132-155]. In total, the effect of CSS on 117 behaviors is summarized. Table 12 shows the converted frequency per day in the absence of CSS, the converted frequency per day with CSS, the percentage increase or decrease, as well as the multiply or divide by factor.

In the right hand third of Table 7 under CSS, the number of behaviors reduced by various percentages is presented. Table 7 shows that 110 of 117 behaviors were reduced by $90 \%$ or more; 112 of 117 by $50 \%$ ormore; and that 5 of 117 topographies continued to occur at the same rate or increased in frequency. Of the 110 topographies reduced by $90 \%$ more, 83 were reduced by $100 \%$.

Frequency Comparisons across FGAs, SGAs, and CSS: The mean frequency of the behaviors treated with each CSS, FGAs, and SGAs are presented in Table 13 (Supplementary File). The table shows that those behaviors treated with CSS occurred at a far higher frequency than those treated with FGAs or SGAs. The table also shows that on the whole, CSS was far more effective in reducing destructive behavior than FGAs or SGAs. 


\begin{abstract}
Discussion

\section{Comparison of Side Effects}

Based upon the current review, the side effects associated with FGAs and SGAs appear to be greater in number, severity, and probability than those associated with CSS. Based upon the data reported by Ray et al. [33], current users of antipsychotic medications are twice as likely to die from sudden cardiac death when compared to non-users and former users. Death can also result from NMS. Both groups of drugs are likely to cause obesity and sexual dysfunction. Obesity, of course, is associated with a host of health risks such as diabetes, heart disease, and cancer. Giving a person with a developmental disability a drug that interferes with appropriate sexual expression adversely affects their quality of life. Generally, SGAs are only marginally safer than FGAs when it comes to the development of TD. Finally, both FGAs and SGAs can cause the person taking them to either be somnolent, sedated, or generally tired. In the placebo controlled studies reported here, this effect was reported in 52\% of those given SGAs compared to $13 \%$ given placebo. In studies without a placebo control, this effect was reported in $40 \%$ of those given SGAs. Those with extremely dangerous or difficult behaviors are likely to be given high doses of FGAs or SGAs, further increasing the probability of sedation.
\end{abstract}

One advantage FGAs and SGAs appear to have over CSS is that they do not cause pain. However, the side effects, administration, and monitoring of these drugs can be painful. Dystonic reactions can be painful and distressing to person experiencing them $[16,157]$. Drugs that are injected intramuscularly can cause acute pain. Venipuncture, necessary for monitoring adverse effects on the body caused by clozapine, also causes pain. Both intramuscular injections and venipuncture can cause panic, avoidance responses, and emotional behavior [158]. The frequency with which these procedures are required is similar to the frequency skin shock is applied after the initial deceleration of the treated behavior.

Across all the studies reviewed, CSS was once associated with tiny pinpoint burns. However, the device in questions was not designed for human use. No other CSS device has ever been reported to cause tissue damage. The other negative side effects described include pain, avoidance responses, and emotional reactions. When considering these side effects, it is important to consider the frequency of use. CSS is applied most frequently during first few days or weeks of treatment. Subsequently, the frequency of use most often decelerates or sometimes drops to zero.

Compared to SGAs and FGAs, the side effects of CSS have not been evaluated in the same depth or with as many participants. In addition, those studying the side effects of antipsychotic drugs generally utilize thorough protocols to assure all side effects are reported. However, because electricity has been applied to the body with therapeutic intensions for more than 100 years, there are well known sequelae of electrical stimulation [159]. These include muscular contraction, burns, seizures, and ventricular fibrillation and are described in detail by Bruner and Leonard [160]. CSS devices designed for humans are never placed over the major motor nerves, head, or chest and lack the power to cause burns, seizures, or ventricular fibrillation. Nevertheless, future research should focus on quantifying and developing standardized measures of negative behavioral side effects.

FGAs, SGAs, and CSS are often used over the long-term. Generally, CSS is used less often over time and therefore, any side effects should be expected to occur less frequently. However, sometimes, the intensity of the stimulus is increased to account for adaptation to a lower intensity. Conversely, many of the negative side effects of FGAs and SGAs are exacerbated with extended use. Specifically, the probability of TD increases approaching an asymptote the longer the exposure to the drug. In addition, SGAs and FGAs contribute to weight gain approaching an asymptote the longer the drug is administered [24].

In summary, based upon the information presented here, the side effects associated with FGAs and SGAs appear to be more numerous and more severe when compared to those associated with CSS.

\section{FGA Efficacy}

The data summarized in this paper show that FGAs are remarkably ineffective in treating destructive behaviors of people with developmental disabilities. The single subject frequency data clearly show that, for the 13 people across 55 topographies, FGAs are not effective in reducing problem behaviors. These findings could be easily dismissed because of the low number of individuals examined. However, the group frequency data in Table 8 confirm the ineffective nature of these drugs in reducing destructive behaviors in 161 people with developmental disabilities. Clearly, there are some cases where the addition of FGAs was extremely effective. For example, in the Mace et al. [111] report, the addition of haloperidol reduced selfinjury by 99 and $100 \%$ in two individuals. However, in the literature, these findings seem to be the exception rather than the rule. The ABC-I data, CGI-I data, and the remaining papers reviewed suggest that FGAs have limited efficacy in treating destructive behaviors.

\section{SGA Efficacy}

ABC-I: ABC-I scores in conditions with SGAs were between 6.55 and $8.78 \mathrm{ABC}-\mathrm{I}$ points less than placebo or baseline conditions. In most cases, these changes were statistically significant. However, of what practical significance are these changes? In order to make such a determination, the properties of the ABC-I require examination.

One ABC-I point corresponds to a move from 3 to 2,2 to 1 , or 1 to 0 on one of 15 items between baseline and the endpoint measure (where 3 is severe problem, 2 is a moderate problem, 1 is a slight problem, and 0 is the absence of a problem). However, as described earlier, the $\mathrm{ABC}$ instructions advise the rater (typically a parent or primary care giver), using temper outbursts as an example, that behavior occurring more often than other class members, even only a few times per week could be rated as a severe problem. To describe severity, the rater also is asked to consider other clients in the class and other clients known by the rater. Thus, depending on the experience of the rater, behavior may be rated as severe, even if the behavior occurred relatively infrequently and regardless of intensity. The diversity of the items in the ABC-I allow for a change of 8 points to represent extraordinary treatment outcomes or simple reductions in verbal disruption. For example, a move from a baseline score of 2 to an endpoint score of 0 on items describing aggression and self-injury (items $2,4,50,52$ ) would represent an excellent outcome. On the other hand, a move from a baseline score of 2 to an endpoint score of 1 on items describing verbal disruption (items $8,10,14,19,29,34,36,41$ ), although beneficial, may obscure a lack of effect on items related to aggression and selfinjury. The specificity described above could be interpreted as asking the ABC-I to do more than it was designed to be. However, unless a specific analysis is conducted to describe the effect of a particular drug on a particular item on the ABC-I, one cannot make conclusions about such effects. 
In most cases, authors make concluding statements that reflect this problem. For example, Marcus et al. [57] reported “....aripiprazole was effective at reducing irritability in children and adolescents with autistic disorder who also demonstrate irritability, agitation, self-injurious behavior, or a combination of these symptoms." This statement reflects the fact that irritability is defined by the 15 items on the ABC-I. If the ABC-I scores decrease, one cannot say for certain that aggression, self-injury, yelling/screaming, or tantrums decreased. McCracken et al. [51] reported "risperidone was safe and effective for the short-term treatment of tantrums, aggression, and self-injurious behavior in children with autistic disorder." Although it may be the case that all of these behaviors as measured by the ABC-I improved as the result of risperidone administration, without a separate analysis, such conclusions cannot be made.

Recently, Aman et al. [161] described the effect of aripiprazole on individual items of the ABC-I. They found the most items were rated lower with aripiprazole when compared to placebo on the ABC-I scale with the exception of self-injury. More of these types of analyses would elucidate the effects of various SGAs on individual behaviors. In addition, it would be helpful to see post hoc data that first classified participants as responders or non-responders, and second described the magnitude of the response. For example, one could report of $\mathrm{N}$ participants receiving the drug, $\mathrm{X}$ showed no change in $\mathrm{ABC}$-I score. Of the remaining Y participants, the ABC-I scores decreased by $Z$. This would allow statements like the following: If this drug is given to $\mathrm{N}$ similar people, it will be effective to $Z$ degree for $Y$ of them.

CGI-I: The shortcomings of the CGI-I have been described [162]. The CGI data show that 53.9 to 57.3 percent of the participants receiving SGA are rated as much or very much improved on the CGI-I. Although clearly there are differential responses to the various drugs, this suggests that just over half of those treated get better as a result of treatment. However, to what degree do they get better? What does much or very much improved on the CGI-I mean? The validity of the CGI-I is largely derived from the requirement that a trained clinician makes the judgment of improvement or deterioration [163]. The question is, then, what information does the clinician use to make their judgment? It would be interesting to determine if CGI-I ratings correlate with changes in behavior frequency or changes in the ABC-I. The CGI-I results are consistent with naturalistic results reported by Lemmon, Gregas, \& Jeste [164] who found that of 80 patients treated with risperidone at a clinic for destructive behaviors, $53 \%$ of them showed some improvement at 1 year.

Frequency data: The frequency data suggest that SGAs are more effective than FGAs in reducing destructive behaviors. The single subject data show that 23 of 136 behaviors (exhibited by 88 different people) were completely eliminated by adding SGAs. In addition, 90 of the 136 behaviors were reduced by $50 \%$ or more. Data from the group studies showed that destructive behaviors were reduced by $59-78 \%$ for 8 of 11 behaviors. Whether this degree of reduction is sufficient depends on the nature of the behavior reduced. For example, if the behavior is sufficiently intense where the emission of only a few responses is likely to cause injury to the person or someone else, reducing a response by even $90 \%$ may not allow the person to enter the community or be free from restraint. In addition, for behavior occurring at high rates, a $50 \%$ reduction may be of little consequence. For example, if a destructive behavior is occurring 2000 times per day and reduced by $50 \%$ to 1000 times per day, we could expect little improvement in his or her living situation, quality of life, or access to the community. For a complete discussion of problems associated with employing percent increases and decreases, see Graf and Lindsley [165].

\section{CSS Efficacy}

This review and analysis suggests that CSS is extremely effective in addressing destructive behaviors. The single subject data show that 83 of 117 behaviors (exhibited by 114 different people) were completely eliminated by adding CSS. In addition, 110 of the 117 behaviors were reduced by $90 \%$ or more. However, it is important to point out that in order to be tolerable, CSS must work rapidly and maintain a low rate of problem behavior. For example, if a behavior occurs 10,000 times per day in the absence of treatment and is reduced by $98 \%$ by CSS, the person would be receiving 200 CSS applications per day; unlikely an acceptable result. Still, the results presented here suggest that indeed CSS is effective to such a degree that the destructive behavior is often completely eliminated.

The results are more remarkable when one considers that the behaviors treated with CSS are likely far more severe and certainly more frequent compared to the behaviors addressed in the medication studies. Specifically, mean daily rate of the behaviors treated with CSS summarized here was equal to 5300.23 , nearly 19 times more frequent than those behaviors treated with SGAs.

\section{Limitations}

There are numerous limitations associated with the overall analysis. First, by limiting the review to only studies where frequency, ABC-I, and CGI-I scores are reported, information is neglected. Dependent variables such as the Children's Psychiatric Rating Scale, Clinical Global Impressions - Severity, and many others were excluded from analysis. Second, studies reporting frequency were included even if weak experimental designs were utilized and/or in the absence of interobserver reliability. Third, to aid in comparison, all frequency data were represented as responses per day. In many cases, frequency data were derived from experimental conditions where a response was measured for a short experimental condition. In some cases, the condition may have transiently increased the frequency of the behavior by presenting stimuli known to evoke problem behaviors or by reinforcing such behaviors. Transient increases in frequency may also have been caused by removing accustomed mechanical restraint. People with developmental disabilities often learn to restore restraint through the emission of high frequency aggressive or selfinjurious behaviors. Thus, in some cases, it is unlikely the response would have continued at the same rate throughout the entire day. Converting from responses per week or month to responses per day is much less problematic. Fourth, the CGI-I and ABC-I were never used to assess the effects of CSS which make cross comparison between interventions impossible. The main advantage of the CGI-I and ABC-I is that they are easy to use and require only a few minutes to complete. Thus, they are much more appropriate for placebo controlled between group designs. Such designs have not been employed with CSS. Fifth, all individual FGAs, SGAs, and CSS interventions were grouped together with respect to side effects and efficacy. Clearly, side effects vary widely among the drugs. In addition, the intensity and severity of side effects associated with CSS could vary with respect to the type of CSS utilized, the behaviors treated, and the individual receiving treatment. Side effects associated with CSS were listed but were not evaluated with a comprehensive validated measure. With regard to efficacy, the tables provided allow readers to extract data with respect to any compound of interest. Regarding CSS, the magnitude and type of the CSS application (duration, intensity, and wave form) are important factors that dictate efficacy and side effects and are not discussed here. Sixth, in many cases, concurrent treatments were 
involved. Many of the drug studies allowed the concurrent treatment with other classes of drugs and other antipsychotics in some cases. In addition, most CSS programs include, at the minimum, differential reinforcement. Finally, at least two studies $[3,50]$ involved some people that emitted destructive behaviors but were not classified as having a developmental disability.

The treatment of a person with destructive behaviors often involves many components including non-antipsychotic medication, a range of behavioral procedures, as well as other treatments. One might argue that medication is simply part of an overall treatment package that is usually successful and therefore CSS is unnecessary. Aman et al. [78], for example, demonstrated that risperidone or aripiprazole combined with simple parent training was more effective than drugs alone. Future research should be devoted to examine such interaction effects.

Mulick and Meinhold [4] point out that financial cost is an additional factor to be considered when choosing among treatments. In terms of labor and administrative costs, designing and implementing a CSS program is far more expensive than prescribing a medication. However, CSS is typically not considered a treatment option until a wide range of medications have failed to reduce the problem behavior(s) to acceptable levels. In addition, in the absence of an effective treatment, people with severe behavior disorders often require 24 hour per day $1: 1,2: 1$, or 3:1 staffing within a residential program. Alternatively, they may spend extended periods of time within psychiatric hospitals where costs are many times higher when compared to a residential or community based programs.

Another factor mentioned by Mulick and Meinhold [4] is social acceptability. They point out that most observers understand the need to treat destructive behaviors. However, Mulick and Meinhold also suggested that some believe using aversive procedures conflict with ideals such as community integration and individual dignity. The current analysis suggests that in many cases, adding CSS to a comprehensive behavior plan may enhance community integration, individual dignity, and improve quality of life. Future research could be devoted to specific questions regarding these factors.

\section{Conclusions}

The decision-making model described by Mikkelsen [5] asks one to consider the following three factors when examining treatment options: severity of symptoms, the probability the treatment will be successful, and the side effect profile of the treatment. Regarding symptom severity, the analysis presented here suggests that the behaviors treated with CSS in the literature are certainly more frequent than those treated with FGAs or SGAs. It is also likely the behaviors treated with CSS were generally more severe in degree. Regarding the probability of treatment success, the present analysis suggests that CSS is by far more effective than SGAs and FGAs in treating severely destructive behaviors. Finally, the negative side effects associated with SGAs and FGAs seem to be more serious, more probable, and more numerous than those associated with CSS. On the other hand, the positive side effects associated with CSS seem more probable and numerous than those associated with SGAs and FGAs.

Unfortunately, due to the ineffective nature of the procedures typically employed, the search for new procedures leads to interventions such as Electroconvulsive Therapy [14], psychosurgery [166], or the continued use of dangerous restraint procedures, as well as relatively ineffective, high risk drugs. As procedures based on behavior function and differential reinforcement continue to be refined, perhaps the need for interventions like CSS will decline. However, it is clear that such procedures are not able to treat all destructive behavior emitted by people with developmental disabilities. Perhaps research on and the development of using CSS treatment-delivery systems to make use of procedures known to be extremely effective for intractable destructive behaviors. The information obtained could be used to inform families with members who exhibit intractable destructive behaviors, lawmakers, and the general public.

\section{Competing Interests}

The author is employed by the Judge Rotenberg Educational Center which manufactures the Graduated Electronic Decelerator (GED). The author has not and does not receive compensation for use or sale of the GED.

\section{References}

1. Matson JL, LoVullo (2008) A review of Behavioral Treatments for SelfInjurious Behaviors of Persons with Autism Spectrum Disorders. Behav Modif 32: 61-76.

2. Wachtel LE, Hagopian LP (2006) Psychopharmacology and applied behavioral analysis: Tandem treatment of severe problem behaviors in intellectual disability and a case series. Isr J Psychiatry Relat Sci 43: 265274.

3. Israel ML, Blenkush NA, von Heyn RE, Rivera PM (2008) Treatment of aggression with behavioral programming that includes supplementary skinshock. The Journal of Behavior Analysis of Offender and Victim Treatment and Prevention 1: 119-166.

4. Meinhold PM, Mulick JA (1992) Social policy and science in the treatment of severe behavior disorders: Defining and securing a healthy relationship. Clinical Psychology Review 12: 585-603.

5. Mikkelsen E (2007) The rationale use of psychotropic medication for individuals with intellectual disabilities. Kingston, NY: NADD Press.

6. Tiger JH, Hanley GP, Bruzek J (2008) Functional communication training: a review and practical guide. Behav Anal Pract 1: 16-23.

7. Chowdhury M, Benson BA(2011) Use of differential reinforcement to reduce behavior problems in adults with intellectual disabilities: a methodological review. Res Dev Disabil 32: 383-94.

8. Carr JE, Severtson JM, Lepper TL (2009) Noncontingent reinforcement is an empirically supported treatment for problem behavior exhibited by individuals with developmental disabilities. Res Dev Disabil 30: 44-57.

9. Smith RG, Iwata BA (1997) Antecedent influences on behavior disorders. J Appl Behav Anal 30: 343-375.

10. Lerman DC, Iwata BA, Wallace MD (1999) Side effects of extinction: prevalence of bursting and aggression during the treatment of self-injurious behavior. J Appl Behav Anal 32: 1-8.

11. Hanley GP, Iwata BA, McCord BE (2003) Functional analysis of problem behavior: a review. J Appl Behav Anal 36: 147-185.

12. Iwata BA, Dorsey MF, Slifer KJ, Bauman KE, Richman GS (1994) Toward a functional analysis of self-injury. J Appl Behav Anal 27: 197-209.

13. Mpakopoulou M, Gatos H, Brotis A, Paterakis KN, Fountas KN (2008) Stereotactic amygdalotomy in the management of severe aggressive behavioral disorders. Neurosurg Focus 25: E6.

14. Wachtel LE, Contrucci-Kuhn SA, Griffin M, Thompson A, Dhossche DM, et al. (2009) ECT for self-injury in an autistic boy. Eur Child Adolesc Psychiatry 18: $458-463$

15. Foxx RM (2004) The national institutes of health consensus development conference on the treatment of destructive behaviors: A study in professional politics. In J.W. Jacobson, R.M. Foxx, \& J.A. Mulick (Eds.), Controversial Therapies for Developmental Disabilities Mahwah, NJ: Lawrence Erlbaum Associates, Inc. 461-476 p. 
Citation: Blenkush N (2017) A Risk-Benefit Analysis of Antipsychotic Medication and Contingent Skin Shock for the Treatment of Destructive Behaviors. Int J Psychol Behav Anal 3: 121. doi: http://dx.doi.org/10.15344/2455-3867/2017/121

Page 11 of 14

16. Marder SR, van Kammen DP (2005) Dopamine receptor antagonists (typical antipsychotics). In B.J. Sadock \& V.A. Sadock (Eds.), Comprehensive Textbook of Psychiatry. Philadelphia, PA: Lippincott Williams \& Wilkins. 2817-2838 p.

17. Aronson JK (Ed.) (2009) Meyler's Side Effects of Psychiatric Drugs Amsterdam: Elsevier

18. Casey DE (1990) Tardive dyskinesia. West J Med 153: 535-541.

19. Tarsy D, Lungu C, Baldessarini RJ (2011) Epidemiology of tardive dyskinesia before and during the era of modern antipsychotic drugs. Handb Clin Neurol 100: 601-616.

20. Tamminga CA, Woerner MG (2002) Clinical course and cellular pathology of tardive dyskinesia. In Davis, Charney, Coyle, \& Nemeroff (Eds.) Neuropsychopharmacology: The Fifth Generation of Progress. (pp. 18311841). Philadelphia, PA: Lippincott Williams \& Wilkins.

21. Rosenheck RA. (2007) Evaluating the cost-effectiveness of reduced tardive dyskinesia with second-generation antipsychotics. $\mathrm{Br} \mathrm{J}$ Psychiatry 191 238-245.

22. Levenson JL (1985) Neuroleptic malignant syndrome. Am J Psychiatry 142 1137-1145

23. Adnet P, Lestavel P, Krivosic-Horber R (2000) Neuroleptic malignan syndrome. Br J Anaesth 85: 129-135.

24. Allison DB, Mentore JL, Moonseong H, Chandler LP, Capelleri JC, et al (1999) Antipsychotic-induced weight gain: A comprehensive research synthesis. Am J Psychiatry 156: 1686-1696.

25. Wang YC, McPherson K, Marsh T, Gortmaker SL, Brown M (2011) Health and economic burden of the projected obesity trends in the USA and the UK. Lancet 378: 815-825

26. Serretti A, Chiesa A (2011) A meta-analysis of sexual dysfunction in psychiatric patients taking antipsychotics. Int Clin Psychopharmacol 26: 130-140.

27. Alldredge BK (1999) Seizure risk associated with psychotropic drugs: clinical and pharmacokinetic considerations. Neurology 53: S68-75.

28. Logothetis J (1967) Spontaneous epileptic seizures and electroencephalographic changes in the course of phenothiazine therapy. Neurology 17: 869-879.

29. PAUIG PM, DELUCA MA, OSTERHELD RG (1961) Thioridazine hydrochloride in the treatment of behavior disorders in epileptics. Am J Psychiatry 117: 832-833.

30. Rosenbloom AL (2010) Hyperprlactinemia with antipsychotic drugs in children and adolescents. Int J Pediatr Endocrinol 2010: 2010.

31. Madhusoodanan S, Parida S, Jimenez C (2010) Hyperprolactinemia associated with psychotropics--a review. Hum Psychopharmacol 25: 281 297.

32. Crawford AM, Beasley CM, Tollefson (1997) The acute and long-term effect of olanzapine compared with placebo and haloperidol on serum prolactin concentrations. Schizophr Res 26: 41-54.

33. Ray WA, Chung CP, Murray KT, Hall K, Stein CM (2009) Atypical antipsychotic drugs and the risk of sudden cardiac death. $\mathrm{N}$ Engl $\mathrm{J}$ Med 360: 225-235.

34. Lehman AF, Lieberman JA, Dixon LB, McGlashan TH, Miller AL, Perkins DO, Kreyenbuhl J (2010) Practice Guideline for the Treatment of Patients with Schizophrenia, $90 \mathrm{p}$

35. Zornberg GL, Jick H (2000) Antipsychotic drug use and risk of first-time idiopathic venous thromboembolism: a case-control study. Lancet 356: 1219-1223.

36. Dayalu P, Chou KL (2008) Antipsychotic-induced extrapyramidal symptoms and their management. Expert Opinions in Pharmacotherapy 9: 1451-1462.

37. Miller DD, Caroff SN, Davis SM, Rosenheck RA, McEvoy JP, et al. (2008) Extrapyramidal side-effects of antipsychotics in a randomised trial. $\mathrm{Br}$ Psychiatry 193: 279-288.

38. Correll CU, Schenk EM (2008) Tardive dyskinesia and new antipsychotics Curr Opin Psychiatry 21: 151-156.

39. Woods SW, Morgenstern H, Saksa JR, Walsh BC, Sullivan MC, et al (2010) Incidence of tardive dyskinesia with atypical versus conventional antipsychotic medications: A prospective cohort study. J Clin Psychiatry 71 : 463-474.

Int J Psychol Behav Anal

ISSN: 2455-3867
40. Troller JN, Chen X, Sachdev PS (2009) Neuroleptic malignant syndrome associated with atypical antipsychotic drugs. CNS Drugs 23: 477-492.

41. Correll CU, Manu P, Olshanskiy V, Napolitano B, Kane JM, et al. (2009) Cardiometabolic Risk of Second-Generation Antipsychotic Medications During First-Time Use in Children and Adolescents. JAMA 302: 1765-1773.

42. Devinsky O, Honigfeld G, Patin J (1991) Clozapine-related seizures Neurology 41: 369-371.

43. Alper K, Schwartz KA Kolts RL, Khan A (2007) Seizure incidence in psychopharmacological clinical trials: an analysis of Food and Drug Administration (FDA) summary basis of approval reports. Biol Psychiatry 62: $345-354$

44. Roke Y, van Harten PN, Boot AM, Buitelaar JK (2009) Antipsychotic medication in children and adolescents: A descriptive review of the effects on prolactin level and associated side effects. J Child Adolesc Psychopharmacol 19: 403-414.

45. Crilly J (2007) The history of clozapine and its emergence in the US market: a review and analysis. Hist Psychiatry 18: 39-60.

46. de la Chapelle A, Kari C, Nurminen M, Hernberg S (1977) Clozapineinduced agranulocytosis. A genetic and epidemiologic study. Hum Genet 37: $183-194$

47. Honigfeld G (1996) Effects of the clozapine national registry system on incidence of deaths related to agranulocytosis. Psychiatr Serv 47: 52-56.

48. Harrison-Woolrych M, Skegg K, Ashton J, Herbison P, Skegg DCG (2011) Nocturnal enuresis in patients taking clozapine, risperidone, olanzapine and quetiapine: comparative cohort study. Br J Psychiatry 199:140-144.

49. McDougle CJ, Holmes JP, Carlson DC, Pelton GH, Cohen DJ, et al. (1998) A double-blind, placebo-controlled study of risperidone in adults with autistic disorder and other pervasive developmental disorders. Arch Gen Psychiatry 55: 633-641.

50. Aman MG, De Smedt G, Derivan A, Lyons B, Findling RL (2002) Doubleblind, placebo-controlled study of risperidone for the treatment of disruptive behaviors in children with subaverage intelligence. Am J Psychiatry 159:1337-1346.

51. McCracken JT, McGough J, Shah B, Cronin P, Hong D, et al. (2002) Risperidone in children with autism and serious behavioral problems. $\mathrm{N}$ Engl J Med 347: 314-321.

52. Shea S, Turgay A, Carroll A, Shulz M, Orlik H, et al. (2004) Risperidone in the treatment of disruptive behavioral symptoms in children with autistic and other pervasive developmental disorders. Pediatrics 114: e643-e641.

53. Gagiano C, Read S, Thorpe L, Eerdekens M, Van Hove I (2005) Shortand long-term efficacy and safety of risperidone in adults with disruptive behavior disorders. Psychopharmacology (Berl) 179: 629-636.

54. Hollander E, Wasserman S, Swanson EN, Chaplin W, Schapiro ML, et al. (2006) A double -blind placebo-controlled pilot study of olanzapine in childhood/adolescent pervasive developmental disorder. J Child Adolesc Psychopharmacol 16: 541-548.

55. Pandina GJ, Bossie CA (2007) Risperidone improves behavioral symptoms in children with autism in a randomized, double-blind, placebo-controlled trial. J Autism Dev Disord 37: 367-373.

56. Owen R, Sikich L, Marcus RN, Corey-Lisle P, Manos G, et al. (2009) Aripiprazole in the treatment of irritability in children and adolescents with autistic disorder. Pediatrics 124: 1533-1540.

57. Marcus RN, Owen R, Kamen L, Manos G, McQuade RD, et al. (2009) A placebo-controlled, fixed-dose study of aripiprazole in children and adolescents with irritability associated with autistic disorder. J Am Acad Child Adolesc Psychiatry 48: 1110-1119.

58. McDougle CJ, Holmes JP, Bronson MR, Anderson GM, Volkmar FR, et al (1997) Risperidone treatment of children and adolescents with pervasive developmental disorders: A prospective, open-label study. J Am Acad Child Adolesc Psychiatry 36: 685-693.

59. Martin A, Koenig K, Scahill L, Bregman J (1999) Open-label quetiapine in the treatment of children and adolescents with autistic disorder. J Child Adolesc Psychopharmacol 9: 99-107.

60. Friedlander R, Lazar, Klancnik J (2001) Atypical antipsychotic use in treating adolescents and young adults with developmental disabilities. Can J Psychiatry 46: 741-745. 
Citation: Blenkush N (2017) A Risk-Benefit Analysis of Antipsychotic Medication and Contingent Skin Shock for the Treatment of Destructive Behaviors. Int J Psychol Behav Anal 3: 121. doi: http://dx.doi.org/10.15344/2455-3867/2017/121

Page 12 of 14

61. Malone RP, Cater J, Sheikh RM, Choudhury MS, Delaney MA (2001) Olanzapine versus haloperidol in children with autistic disorder: An open pilot study. J Am Acad Child Adolesc Psychiatry 40: 887-894.

62. Masi G, Cosenza A, Mucci M, Brovedani P (2001) Open trial of risperidone in 24 young children with pervasive developmental disorders. J Am Acad Child Adolesc Psychiatry 40: 1206-1214.

63. Kemner C, Willemsen-Swinkels SH, de Jonge $M$, Tuynman-Qua $H$ van Engeland $\mathrm{H}$ (2002) Open-label study of olanzapine in children with pervasive developmental disorder. J Clin Psychopharmacol 22: 455-460.

64. Malone RP, Maislin G, Choudhury MS, Gifford C, Delaney MA (2002) Risperidone treatment in children and adolescents with autism: short- and long-term safety and effectiveness. J Am Acad Child Adolesc Psychiatry 41: $140-147$

65. McDougle CJ, Kem DL, Posey DJ (2002) Case series: use of ziprasidone for maladaptive symptoms in youths with autism. J Am Acad Child Adolesc Psychiatry 41: 921-927.

66. Masi G, Cosenza A, Mucci M, Brovedani P (2003) A 3-year naturalistic study of 53 preschool children with pervasive developmental disorders treated with risperidone. J Clin Psychiatry 64: 1039-1047.

67. Gagliano A, Germano E, Pustorino G, Impallomeni C, D'Arrigo C, et al. (2004) Risperidone treatment of children with autistic disorder: Effectiveness, tolerability, and pharmacokinetic implications. J Child Adolesc Psychopharmacol 14: 39-47.

68. Stavrakaki C, Antochi R, Emery PC (2004) Olanzapine in the treatment of pervasive developmental disorders: a case series analysis. J Psychiatry Neurosci 29: 57-60.

69. Stigler KA, Posey DJ, McDougle CJ (2004) Aripiprazole for maladaptive behavior in pervasive developmental disorders. J Child Adolesc Psychopharmacol 14: 455-463.

70. Findling RL, McNamara NK, Gracious BL, O'Riordan MA, Reed MD, et al. (2004) Quetiapine in nine youths with autistic disorder. J Child Adolesc Psychopharmacol 14: 287-294.

71. Corson AH, Barkenbus JE, Posey DJ, Stigler KA, McDougle CJ (2004) A retrospective analysis of quetiapine in the treatment of pervasive developmental disorders. J Clin Psychiatry 65: 1531-1536.

72. Hardan AY, Jou RJ, Handen BL (2005) Retrospective study of quetiapine in children and adolescents with pervasive developmental disorders. J Autism Dev Disord 35: 387-391.

73. Rugino TA, Janvier YM (2005) Aripiprazole in children and adolescents: clinical experience. J Child Neurol 20: 603-610.

74. Malone RP, Delaney MA, Hyman SB, Cater JR (2007) Ziprasidone in adolescents with autism: an open-label pilot study. J Child Adolesc Psychopharmacol 17: 779-790.

75. Capone GT, Goyal P, Grados M, Smith B, Kammann H (2008) Risperidone use in children with down syndrome, severe intellectual disability, and comorbid autistic spectrum disorders: A naturalistic study. J Dev Behav Pediatr 29: 106-116.

76. Stigler KA, Diener JT, Kohn AE, Li L, Erickson CA, Posey DJ, McDougle CJ (2009) Aripiprazole in pervasive developmental disorder not otherwise specified and asperger's disorder: A 14-week, prospective, open-label study. J Child Adolesc Psychopharmacol 19: 265-274.

77. Amore M, Bertelli M, Villani D, Tamborini S, Rossi M (2011) Olanzapine vs. risperidone in treating aggressive behaviours in adults with intellectual disability: a single blind study. J Intellect Disabil Res 55: 210-218.

78. Aman MG, McDougle CJ, Scahill L, Handen B, Arnold LE, et al. (2009) Medication and parent training in children with pervasive developmental disorders and serious behavior problems: Results from a randomized clinical trial. J Am Acad Child Adolesc Psychiatry 48:1143-1154.

79. Hellings JA, Zarcone JR, Reese RM, Valdovinos MG, Marquis JG, et al. (2006) A crossover study of risperidone in children, adolescents and adults with mental retardation. J Autism Dev Disord 36: 401-411.

80. Zarcone JR, Hellings JA, Crandall K, Reese RM, Marquis J, et al. (2001) Effects of risperidone on aberrant behavior of persons with developmental disabilities: I. A double-blind crossover study using multiple measures. Am J Ment Retard 106: 525-538.

81. Troost PW, Lahuis BE, Steenhuis MP, Ketelaars CE, Buitelaar JK, et al (2005) Long-term effects of risperidone in children with autism spectrum disorders: a placebo discontinuation study. J Am Acad Child Adolesc Psychiatry 44: 1137-1144.82.

Int J Psychol Behav Anal

ISSN: 2455-3867
82. Cohen SA, Underwood MT (1994) The use of clozapine in a mentally retarded and aggressive population. J Clin Psychiatry 55: 440-444.

83. Janowsky DS, Barnhill LJ, Davis JM (2003) Olanzapine for self-injurious, aggressive, and disruptive behaviors in intellectually disabled adults: A retrospective, open-label, naturalistic trial. J Clin Psychiatry 64: 1258-1265.

84. Lott RS, Kerrick JM, Cohen SA (1996) Clinical and economic aspects of risperidone in adults with mental retardation and behavioral disturbance. Psychopharmacol Bull 32: 721-729.

85. Cohen SA, Ihrig K, Lott RS, Kerrick JM (1998) Risperidone for aggression and self-injurious behavior in adults with mental retardation. J Autism Dev Disord 28: 229-233.

86. McMurtry CM, Noel M, Chambers CT, McGrath PJ (2011) Children's fear during procedural pain: preliminary investigation of the Children's Fear Scale. Health Psychol 30: 780-788.

87. Frazier TW, Youngstrom EA, Haycook T, Sinoff A, Dimitriou F, et al (2010) Effectiveness of medication combined with intensive behavioral interventions for reducing aggression in youth with autism spectrum disorder. J Child Adolesc Psychopharmacol 20: 167-177.

88. Durand VM (1982) A behavioral/pharmacological intervention for the treatment of severe self-injurious behavior. J Autism Dev Disord 12: 243251.

89. Lichstein KL, Schreibman L (1976) Employing electric shock with autistic children. A review of the side effects. J Autism Child Schizophr 6: 163-173.

90. Matson JL, Taras ME (1989) A 20 year review of punishment and alternative methods to treat problem behaviors in developmentally delayed persons. Res Dev Disabil 10: 85-104.

91. Mudford OC, Boundy K, Murray AD (1995) Therapeutic shock device (TSD): clinical evaluation with self-injurious behaviors. Res Dev Disabil 16 : 253-267

92. Duker PC, Seys DM (1996) Long-term use of electrical aversion treatment with self-injurious behavior. Res Dev Disabil 17: 293-301.

93. Duker PC, Seys DM (2000) A quasi-experimental study on the effect of electrical aversion on imposed mechanical restraint for severe self-injurious behavior. Res Dev Disabil 21: 235-242.

94. Duker PC, Van den Munckhof M (2007) Heart rate and the role of the active receiver during contingent electric shock for severe self-injurious behavior. Res Dev Disabil 28: 43-49.

95. Linscheid TR, Iwata BA, Ricketts RW, Williams DE, Griffin JC (1990) Clinical evaluation of the self-injurious behavior inhibiting system (SIBIS). J Appl Behav Anal 23: 53-78.

96. Ricketts R, Goza A, Matese M (1992) Case study: Effects of Naltrexone and SIBIS on self-injury. Behavioral Residential Treatment 7: 315-326.

97. Williams DE, Kirkpatrick-Sanchez S, Iwata BA (1993) A comparison of shock intensity in the treatment of longstanding and severe self-injurious behavior. Res Dev Disabil 14: 207-219.

98. Linscheid TR, Pejeau C, Cohen S, Footo-Lenz M (1994) Positive side effects in the treatment of SIB using the Self-Injurious Behavior Inhibiting System (SIBIS): Implications for operant and biochemical explanations of SIB. Res Dev Disabil 15:81-90.

99. Linscheid TR, Reichenbach H (2002) Multiple factors in the long-term effectiveness of contingent electric shock treatment for self-injurious behavior: a case example. Res Dev Disabil 23: 161-177.

100. Salvy S, Mulick JA, Butter E, Bartlett RK, Linscheid TR (2004) Contingent electric shock (SIBIS) and a conditioned punisher eliminate severe head banging in a preschool child. Behavioral Interventions 19: 59-72.

101. van Oorsouw WM, Israel ML, von Heyn RE, Duker PC (2008) Side effects of contingent shock treatment. Res Dev Disabil 29: 513-523.

102. Israel ML, Blenkush NA, von Heyn RE, Sands CC (2010) Seven case studies of individuals expelled from positive-only programs. Journal of Behavior Analysis of Offender and Victim Treatment and Prevention 2: 2036.

103. Guy W (1976) ECDEU Assessment Manual for Psychopharmacology Rockville, MD, U.S. Deparment of Health, Education, and Welfare. 218222 pp.

104. Green VA, O'Reilly M, Itchon J, Sigafoos J (2005) Persistence of early emerging aberrant bhavior in children with developmental disabilities. Res Dev Disabil 26: 47-55. 
Citation: Blenkush N (2017) A Risk-Benefit Analysis of Antipsychotic Medication and Contingent Skin Shock for the Treatment of Destructive Behaviors. Int J Psychol Behav Anal 3: 121. doi: http://dx.doi.org/10.15344/2455-3867/2017/121

Page 13 of 14

105. Green VA, O'Reilly M, Itchon J, Sigafoos J (2005) Persistence of early emerging aberrant behavior in children with developmental disabilities. Res Dev Disabil 26: 47-55.

106. Lindsley OR (1964) Direct measurement and prosthesis of retarded behavior. Journal of Education 147:62-81.

107. Johnston JM, Pennypacker HS (1980) Strategies and tactics of human behavioral research. Hillsdale, NJ: Erlbaum.

108. Thompson T, Hackenberg TD, Schall DW (1991) Pharmacologica Treatments for Behavior Problems in Developmental Disabilities. In Treatment of Destructive Behaviors in Persons with Developmenta Disabilities, Bethesda, MD: NIH Consensus Development Conference, pp. 343- 439.

109. Singh NN, Landrum TJ, Ellis CR, Donatelli LS (1993) Effects of thioridazine and visual screening on stereotypy and social behavior in individuals with mental retardation. Res Dev Disabil 14: 163-177.

110. May P, London EB, Zimmerman T, Thompson R, Mento T, et al. (1995) A study of the clinical outcome of patients with profound mental retardation gradually withdrawn from chronic neuroleptic medication. Ann Clin Psychiatry 7:155-160.

111. Mace FC, Blum NJ, Sierp BJ, Delaney BA, Mauk JE (2001) Differential response of operant self-injury to pharmacologic versus behaviora treatment. J Dev Behav Pediatr 22: 85-91.

112. Janowsky DS, Barnhill LJ, Shetty M, Davis JM (2005) Minimally effective doses of conventional antipsychotic medications used to treat aggression self-injurious and destructive behaviors in mentally retarded adults. J Clin Psychopharmacol 25: 19-25.

113. Miral S, Gencer O. Inal-Emiroglu FN, Baykara B, Baykara A, Dirik E (2008) Risperidone versus haloperidol in children and adolescents with AD. Eur Child Adolesc Psychiatry 17: 1-8.

114. Gencer O, Emiroglu FN, Miral S, Baykara B, Baykara A, et al. (2008) Comparison of long-term efficacy and safety of risperidone and haloperido in children and adolescents with autistic disorder. An open label maintenance study. Eur Child Adolesc Psychiatry 17: 217-225.

115. Tyrer P, Oliver-Africano PC, Ahmed Z, Bouras N Cooray, S. Deb, S..... Crawford, M. (2008). Risperidone, haloperidol, and placebo in the treatment of aggressive challenging behaviour in patients with intellectual disability: a randomized controlled trial. Lancet 371: 57-63

116. White TJ, Aman MG (1985) Pimozide treatment in disruptive severely retarded patients. Aust N Z J Psychiatry 19: 92-94.

117. Aman MG, White AJ (1988) Thioridazine dose effects with reference to stereotypic behavior in mentally retarded residents. J Autism Dev Disord 18: 355-366.

118. Aman MG, Teehan CJ., White AJ, Turbott SH, Vaithianathan C (1989) Haloperidol treatment with chronically medicated residents: Dose effects on clinical behavior and reinforcement contingencies. Am J Ment Retard 93:452-460.

119. Perry R, Campbell M, Adams P, Lynch N, Spencer EK, et al. (1989) Long-term efficacy of haloperidol in autistic children: Continuous versus discontinuous drug administration. J Am Acad Child Adolesc Psychiatry 28 87-92

120. Millichamp CJ, Singh NN (1987) The effects of intermittent drug therapy on stereotypy and collateral behaviors of mentally retarded persons. Res Dev Disabil 8: 213-227.

121. Burgio LD, Page TJ, Capriotti RM (1985) Clinical behavioral pharmacology: Methods for evaluating medications and contingency management. J App Behav Anal 18: 45-59.

122. Luiselli JK (1986) Behavior analysis of pharmacological and contingency management interventions for self-injury. J Behav Ther Exp Psychiatry 17: 275-284

123. Heistad GT, Zimmermann RL, Doebler MI (1982) Long-term usefulness of thioridazine for institutionalized mentally retarded patients. Am J Ment Defic 87: $243-251$

124. Perry R, Pataki C, Munoz-silva DM, Armenteros J (1997) Risperidone in Children and Adolescents with pervasive developmental disorder: Pilot trial and follow-up. J Child Adolesc Psychopharmacol 7: 167-179.

125. Nicolson R, Awad G, Sloman L (1998) An open trial of risperidone in young autistic children. J Am Acad Child Adolesc Psychiatry 37: 372-376.
126. Fido A, Al-Saad S (2008) Olanzapine in the treatment of behavioral problems associated with autism: an open-label trial in Kuwait. Med Princ Pract 17: 415-418.

127. Marcus RN, Owen R, Manos G Mankoski R, Kamen L et al. (2011) Aripiprazole in the treatment of irritability in pediatric patients (aged 6-17 years) with autistic disorder: Results from a 52-week, open-label study. J Child Adolesc Psychopharmacol 21: 229-236.

128. Dartnall NA, Holmes JP, Morgan SN, McDougle CJ (1999) Brief Report Two-year control of behavioral symptoms with risperidone in two profoundly retarded adults with autism. J Autism Dev Disord 29: 87-91.

129. Crosland KA, Zarcone JR, Lindauer SE, Valdovinos MG, Zarcone TJ, et al. (2003) Use of functional analysis methodology in the evaluation of medication effects. J Autism Dev Disord 33: 271-279.

130. Ruedrich SL, Swales TP, Rossvanes C, Diana L Arkadiev V, et al. (2008). Atypical antipsychotic medication improves aggression but not selfinjurious behaviour, in adults with intellectual disabilities. J Intellect Disabil Res 52:132-140.

131. Tate BG, Baroff GS (1966) Aversive control of self-injurious behavior in a psychotic boy. Behav Res Ther 4: 281-287.

132. Baroff GS, Tate BG (1968) The use of aversive stimulation in the treatment of chronic self-injurious behavior. J Am Acad Child Psychiatry 7: 454-470.

133. Risley TR (1968) The effects and side effects of punishing the autistic behaviors of a deviant child. J Appl Behav Anal 1: 21-34.

134. Whaley D, Tough J (1968) Treatment of a self-injuring mongoloid with shock-induced suppression and avoidance. Michigan Mental Health Research Bulletin 2: 33-35.

135. Kushner M (1969) Faradic aversive controls in clinical practice. In: C Nueringer \& I.L. Michael (Eds.) Behavior modification in clinical psychology, 26-51 p.

136. Lovaas OI, Simmons JQ (1969) Manipulation of self-destruction in three retarded children. J Appl Behav Anal 2: 143-157.

137. Ludwig AM, Marx AJ, Hill PA, Browning RM (1969) The control of violent behavior through faradic shock. J Nerv Ment Dis 148: 624-637.

138. Kohlenberg RJ (1970) The punishment of persistent vomiting: a case study. J Appl Behav Anal 3: 241-245.

139. Kohlenberg RJ (1970) The punishment of persistent vomiting: a case study. J Appl Behav Anal 3: 241-245

140. Bucher B, King LW (1971) Generalization of punishment effects in the deviant behavior of a psychotic child. Behavior Therapy 2: 68-77.

141. Corte HE, Wolf MM, Locke BJ (1971) A comparison of procedures for eliminating self-injurious behavior of retarded adolescents. J Appl Behav Anal 4: 201-213

142. Baumeister AA, Forehand R (1972) Effects of contingent shock and verbal command on body rocking of retardates. J Clin Psychol 28: 586-590.

143. Tate BG (1972) Case study: Control of chronic self-injurious behavior by conditioning procedures. Behavior Therapy 3:72-83.

144. Brandsma JM, Stein LI (1973) The use of punishment as a treatment modality: a case report. J Nerv Ment Dis 156: $30-37$.

145. Hall H, Thorne DE, Shinedling M, Sagers PS (1973) Overcoming situationspecific problems associated with typical institutional attempts to suppress self-mutilative behavior. Train Sch Bull (Vinel) 70:111-114.

146. Merbaum M (1973) The modification of self-destructive behavior by a mother-therapist using aversive stimulation. Behavior Therapy 4:442-447.

147. Wright $L$ (1973) Aversive conditioning of self-induced seizures. Behavior Therapy 4:712-713.

148. Prochaska J, Smith N, Marzilli R, Colby J, Donovan W (1974) Remotecontrol aversive stimulation in the treatment of head-banging in a retarded child. Journal of Behavior Therapy and Experimental Psychiatry 5:285-289.

149. Ramey G (1974) Use of electric shock in the classroom: The remediation of self abusive behavior in a retarded child. Behavioral Engineering 1: 4-9.

150. Young JA, Wincze JP (1974) The effects of the reinforcement of compatible and incompatible alternative behaviors on the self-injurious and related behaviors of a profoundly retarded female adult. Behavior Therapy 5:614 623 
Citation: Blenkush N (2017) A Risk-Benefit Analysis of Antipsychotic Medication and Contingent Skin Shock for the Treatment of Destructive Behaviors. Int J Psychol Behav Anal 3: 121. doi: http://dx.doi.org/10.15344/2455-3867/2017/121

Page 14 of 14

151. Ball T, Sibbach $L$, Jones R, Steele B, Frazier L (1975) An accelerometeractivated device to control assaultive and self-destructive behaviors in retardates. Behavior Therapy and Experimental Psychiatry 6: 223-228.

152. Romanczyk RG, Goren ER (1975) Severe self-injurious behavior: the problem of clinical control. J Consult Clin Psychol 43: 730-739.

153. Duker PC (1976) Remotely applied punishment versus avoidance conditioning in the treatment of self-injurious behaviors. European Journal of behavior Analysis and Modification, 3:179-184.

154. Anderson L, Dancis J, Alpert M (1978) Behavioral contingencies and selfmutilation in Lesch-Nyhan disease. J Consult Clin Psychol 46: 529-536.

155. Foxx RM, Bittle RG, Faw GD (1989) A maintenance strategy for discontinuing aversive procedures: a 52-month follow-up of the treatment of aggression. Am J Ment Retard 94: 27-36.

156. Dressler D, Benecke R (2005) Diagnosis and management of acute movement disorders. J Neurol 252: 1299-1306.

157. Dressler D, Benecke R (2005) Diagnosis and management of acute movement disorders. J Neurol 252: 1299-1306.

158. Caprilli S, Anastasi F, Grotto RP, Scollo Abeti M, Messeri A (2007) Interactive music as a treatment for pain and stress in children during venipuncture: a randomized prospective study. J Dev Behav Pediatr 28: 399-403.

159. Bruner JMR (1994 September 16) Letter to the Judge Rotenberg Center. Copy in possession of The Judge Rotenberg Center.

160. Bruner JMR, Leonard PF (1989) Electricity, Safety, and the Patient Chicago, Illinois: Year Book Medical Publishers, INC

161. Aman MG, Kasper W, Manos G, Mathew S, Marcus R, et al. (2010) LineItem Analysis of the Aberrant Behavior Checklist: Results from Two Studies of Aripiprazole in the Treatment of Irritability Associated with Autistic Disorder. J Child Adolesc Psychopharmacol 20: 415-422.

162. Beneke M, Rasmus W (1992) "Clinical Global Impressions" (ECDEU): some critical comments. Pharmacopsychiatry 25: 171-176.

163. Berk M, Ng F, Dodd S, Callaly T, Campbell S, et al. (2008) The validity of the CGI severity and improvement scales as measures of clinical effectiveness suitable for routine clinical use. J Eval Clin Pract 14: 979-983.

164. Lemmon ME, Gregas M, Jeste SS (2011) Risperidone use in autism spectrum disorders: A retrospective review of a clinic-referred patient population. J Child Neurol 26: 428-432.

165. Graf S, Lindsley OR (2002) Standard Celeration Charting 2002. Graf Implements: Poland, Ohio.

166. Fountas KN, Smith JR, Lee GP (2007) Bilateral stereotactic amygdolotomy for self-mutilation disorder report and review of the literature. Stereotact Funct Neurosurg 85:121-128. 